\title{
Synthesis of a new serie of quinoline-carboxamides based on methylated aminoesters: NMR characterization and antimicrobial activity
}

\author{
Oussama Moussaoui ${ }^{1}$, El Mestafa EL Hadrami ${ }^{1}$, Ghita Benjelloun Touimi ${ }^{2}$, Bahia Bennani ${ }^{2}$, Abdeslem \\ Ben Tama ${ }^{1}$, Youssef Kandri Rodi ${ }^{1}$, Said Chakroune ${ }^{1, *}$, Abdellatif Boukir ${ }^{3}$ \\ ${ }^{1}$ Laboratory of Applied Organic Chemistry, Sidi Mohamed Ben Abdellah University, Faculty of Sciences and \\ Techniques, BP 2202 Fez, Morocco \\ ${ }^{2}$ Laboratory of Human Pathology, Biomedicine and Environment, Sidi Mohamed Ben Abdellah University, \\ Faculty of Medicine and Pharmacy, 1893 - KM 2200 Route Sidi Harazem Fez, 30070, Morocco \\ ${ }^{3}$ Laboratory of Microbial Biotechnology and Molecular Bioactives, Sidi Mohamed Ben Abdellah University, \\ Faculty of Sciences and Techniques, BP 2202 Fez, Morocco
}

\begin{abstract}
Ten new quinoline-carboxamides have been synthesized using the coupling reaction between 2-oxo1,2-dihydroquinoline-4-carboxylic acid as a substrate and five different amino ester at room temperature with basic media (triethylamine). The products were obtained with a good yield ranging from 60 to $80 \%$ and were structurally characterized by ${ }^{1} \mathrm{H}$ and ${ }^{13} \mathrm{C}$ NMR spectroscopy and mass spectrometry. The antibacterial activities of the synthesized compounds have been evaluated against 9 strains of bacteria and compared to references (erythromycin, ofloxacin, ticarcillin, oxacillin, ampicillin, norfloxacin, ceftazidim, cefotaxim). The results showed that the majority of carboxamides-quinoline ester groups present a larger inhibition diameters than those of the antibiotics references. The highest antibacterial activity in vitro against the Enterococcus feacalis has been revealed for compound 1a (methyl 2-oxo-1.2-dihydroquinoline-4-yl- $L$-alaninate).
\end{abstract}

Keywords: Quinoline, peptidic coupling, amino acids, antibacterial activity, ${ }^{1} \mathrm{H}$ and ${ }^{13} \mathrm{C} \mathrm{NMR}$, mass spectrometry.

\section{Introduction}

Antibiotics based on heterocycles pharmacophore present a great interest and play a central role in the medicinal sector during this century, especially due to their potential effects against bacterial infections, however bacterial cells have developed some resistance and are able to defend themselves against the antibiotic. The increasing of this resistance phenomenon towards antibiotics has been described as a global public health menace ${ }^{1}$.

Quinolones is among the most synthesized antibiotics that have been widely used by scientists to synthesize new antibacterial agent. In 1962, the first quinolone directly derived from 7-chloroquinoline was discovered to be nalidixic acid (Figure 1: I), which is indicated for the treatment of urinary tract infection ${ }^{2}$.

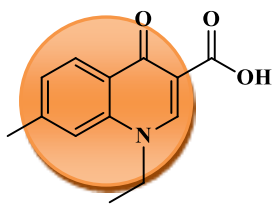

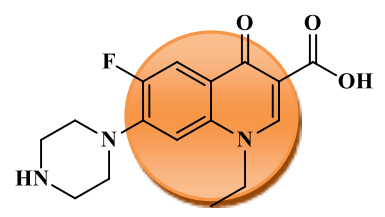

II

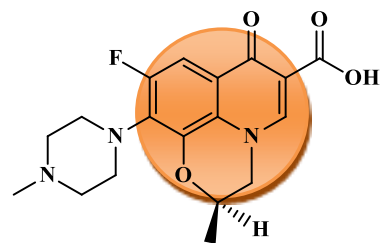

III

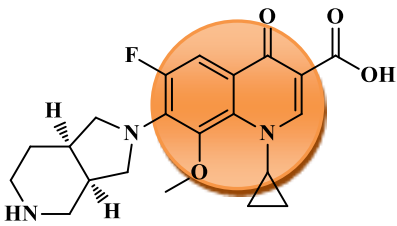

IV

Figure 1. Structures of nalidixic acid: I, norfloxacin: II, levofloxacin: III and moxifloxacin: IV.

Other derivatives, such as fluoroquinolones (norfloxacin, levofloxacin, ofloxacine, lomefloxacin, etc), were synthesized by grafting both fluoro group at the position 6 and piperazine at the position 7 of the *Corresponding author: Said Chakroune

Email address: said.chakroune@usmba.ac.ma

DOI: http://dx.doi.org/10.13171/mjc941911231077sc quinolines substrate. Regarding the norfloxacin (Figure 1: II), it constitutes the second generation of fluoroquinolone presenting an increase in activity against Gram+ ${ }^{3}$. While in the case of $3^{\text {rd }}$ generation

Received September 17, 2019

Accepted October 28, 2019

Puplished November 23, 2019 
fluoroquinolone, such as, levofloxacin (Figure 1: III), a large spectrum activities was manifested against Gram $^{+}$and Gram $^{-}$bacteria ${ }^{4}$. Concerning the structure-activity of moxifloxacin fluoroquinolone drug of $4^{\text {th }}$ generation (Figure 1: IV), it was obtained by incorporating methoxyl group at position 8 and bicyclo-1,5-diamine at the position 7 . The structural modification induced a change with improving the activity and conferring some efficiency treatment against pneumologic infections ${ }^{5}$.

Some quinoline derivatives have been also synthesized and know by their antibacterial activities 6 , potent intestinal antiseptic ${ }^{7}$, agent anticancer ${ }^{8}$, analgesic ${ }^{9}$, antiallergic ${ }^{10}$, used for the treatment of Alzheimer's disease (AD) ${ }^{11}$, antitinephritic ${ }^{12}$, antiplasmodial activity 13, antimalarial 14, antihypertensive ${ }^{15}$, anti-HIV 16 and present an antitumoral activities ${ }^{17}$.

The development of new synthetic heterocycles quinoline presents a major strategy and challenge for their synthesis and the discovery of new promising drug candidate able to present a potent pharmacological and therapeutic activities.

Amino acids are considered as major constituents of many drugs, such as $\beta$-lactams antibiotics ${ }^{18}$ and glutamate antagonists ${ }^{19}$. Tyrosine, phenylalanine, and tryptophan are well known for their essential role in the living organism and present a potent and wide range of therapeutic activities ${ }^{20}$ and also present antioxidant activity ${ }^{21}$. In order to study the biological and pharmacological activities of amino acids, some researchers have been carried out the modifications on amino acid groups by coupling than to other heterocyclic compounds, such as coumarine 22-23. Shivaraj et al. $2013^{24}$ have shown that a serie of quinoline-6-carboxamides based on primary amines present an antibacterial activity in vitro against Escherichia coli and Staphyllococcus aureus, converting them with glycosidic ring to surfactants 25 to ligand metal complexes ${ }^{26}$ and/or to hydrogels ${ }^{27}$. Similarly, Zhang et al. $2003{ }^{28}$ synthesized and demonstrated that $\mathrm{Cu}(\mathrm{II})$ complexes with the ligand $\mathrm{N}$-(8-quinolyl) pyridin-2-carboxamide showed cytotoxicity against murine leukaemia P-388 and human leukaemia cell lines HL-60. Recently, Filali Baba et al. $2019{ }^{29}$ have reported that the serie of 2oxo-1,2-dihydroquinoline-4-carboxylate derivatives presents an interesting antioxidant activity. In our case study, we have tried to graft new quinoline heterocyclic compounds to a serie of amino esters groups in order to provide some interesting biological activities.
In this work, we report the synthesis of ten new quinoline-4-carboxamides compounds. Their structural characterizations by both Nuclear Magnetic Resonance ${ }^{1} \mathrm{H}$ and ${ }^{13} \mathrm{C}$ and mass-spectrometry, as well as, the evaluation of their antibacterial activities against 9 types of bacteria.

\section{Results and Discussion}

\subsection{Synthesis of quinoline-carboxamides}

Our study concerned the synthesis of two types of serie of quinoline-carboxamides derivatives, 2-oxo1,2-dihyquinoline-4-carboxamides and 6-bromo-2oxo-1,2-dihyquinoline-4-carboxamides by reacting a quinolinic acid as a substrate with five types of various amino methyl esters groups (L-alanine-OMe, L-phenylalanine-OMe, L-phenylglycine-OMe, LSerine-OMe and L-tryptophane-OMe) during 12 hours at room temperature with the presence of hexafluorophosphate benzotriazole tetramethyl uronium (HBTU) as a coupling agent in basic medium using triethylamine (TEA) and dimethylformamide (DMF) as a suitable solvent for this type of reaction. The five amino acids (alanine, serine, phenylglycine, phenylalanine and tryptophan) were converted towards their methylated esters groups, The synthesized compounds purified on liquid chromatography column using silica gel as a stationary phase and were obtained with good yields ranging from 60 to $80 \%$. Their chemical structures were elucidated by both techniques ${ }^{1} \mathrm{H}$ and ${ }^{13} \mathrm{C}$ NMR and mass-spectrometry.

In order to synthesize the quinoline-carboxamides, the first step requires the preparation of two types of quinoline substrates: 2-oxo-1,2-dihydroquinoline-4carboxylic acid $\mathbf{1}$ and 6-bromo-2-oxo-1,2dihydroquinoline-4-carboxylic acid $\mathbf{2}$, which are obtained by reacting the malonic acid on both isatin and its bromo-derivatives with the presence of sodium acetate. The reaction was performed under reflux of acetic acid during 24 hours ${ }^{30}$ (Scheme 1).

Before the preparation step of quinolinecarboxamides, the five amino acids were converted to their methylated amino esters by the action of thionyl chloride $\left(\mathrm{SOCl}_{2}\right)$ on amino acid in methanol under reflux ${ }^{31}$. In the second step, ten new quinolinecarboxamides products $(\mathbf{1} \mathbf{a} \rightarrow \mathbf{1 e}$ and $\mathbf{2 a} \rightarrow \mathbf{2 e})$ were obtained (Scheme 1) by coupling reaction between each substrate (1 and $\mathbf{2}$ ) with the five different types of methylated amino esters hydrochloric acid salt (L-alanine-OMe, L-phenylalanine-OMe, L-phenylglycine-OMe, L-serine-OMe and L-tryptophane-OMe). The differents synthesized products are illustrated in both Scheme 1 and Table 1. 


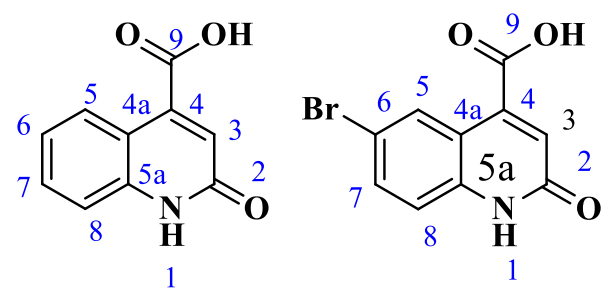

12

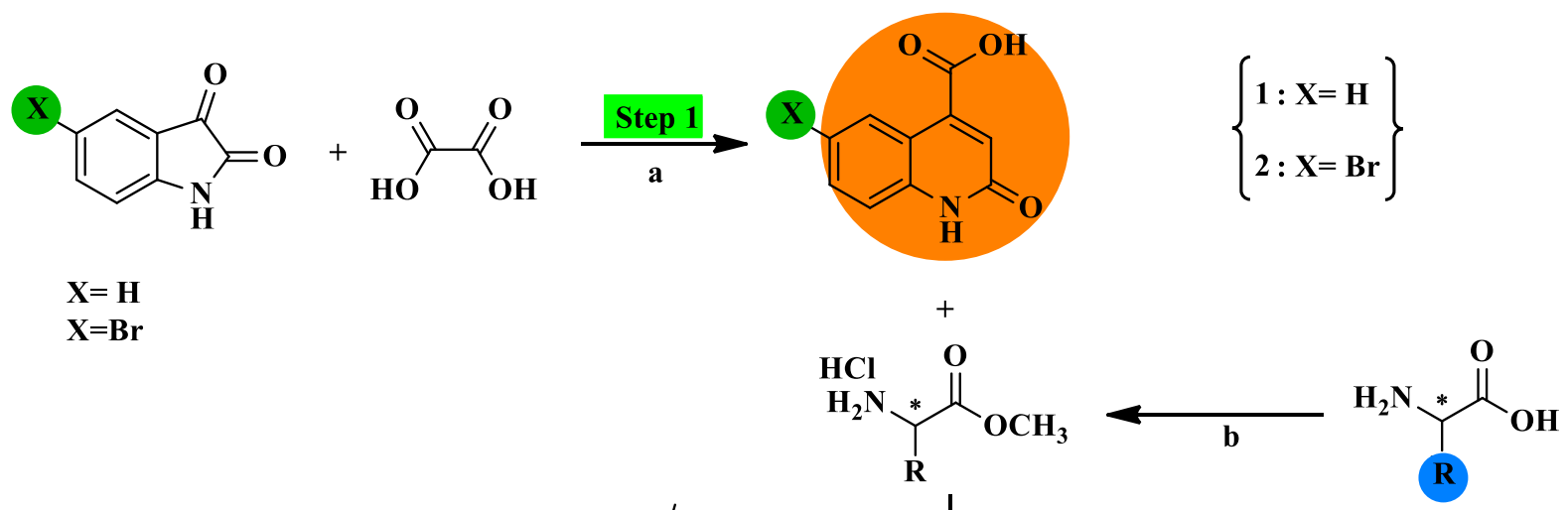<smiles>[R]CCOCc1ccccc1</smiles>

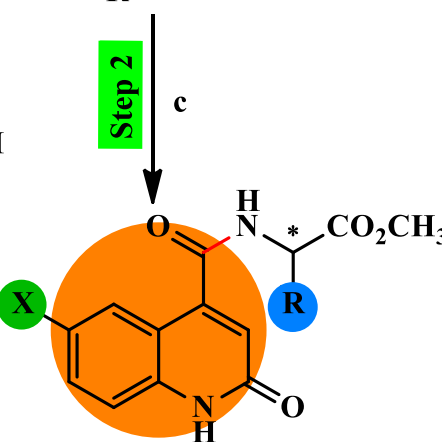

$\left\{\begin{array}{cc}1 a-1 e & : X=H \\ 2 a-2 e & : X=B r\end{array}\right\}$

Scheme 1. Reagent: (a) sodium acetate, acetic acid, 24h reflux ${ }^{30}$; (b) $\mathrm{SOCl}_{2}, \mathrm{Methanol}^{2}$ h reflux ${ }^{31}$; (c) HBTU, TEA, $12 \mathrm{~h}^{32}$.

Table 1. Synthesized quinoline-carboxamides.

\begin{tabular}{|c|c|c|c|}
\hline $\begin{array}{c}\text { Quinoline } \\
\text { carboxylic } \\
\text { Acid } \\
\text { substrate }\end{array}$ & amino esters & Produc & $\begin{array}{c}\text { Yield } \\
\%\end{array}$ \\
\hline 1 & $\underset{\text { L-ala }}{\mathrm{HCl}} \overbrace{\mathrm{H}_{2} \mathrm{~N}}^{\mathrm{CO}_{3}}$ & $\underbrace{\mathrm{O}_{\mathrm{H}}^{\mathrm{N}} \underbrace{\mathrm{O}}_{\mathrm{CH}_{3}} \mathrm{OCH}_{3}}_{1 \mathrm{H}}$ & 75 \\
\hline 1 & $\underset{\mathrm{L}-\mathrm{ser}}{\mathrm{HCl}} \stackrel{\mathrm{H}_{2} \mathrm{~N}}{\mathrm{CO}_{2} \mathrm{CH}_{3}}$ & 1b & 70 \\
\hline 1 & L-phgly & 1c & 65 \\
\hline
\end{tabular}




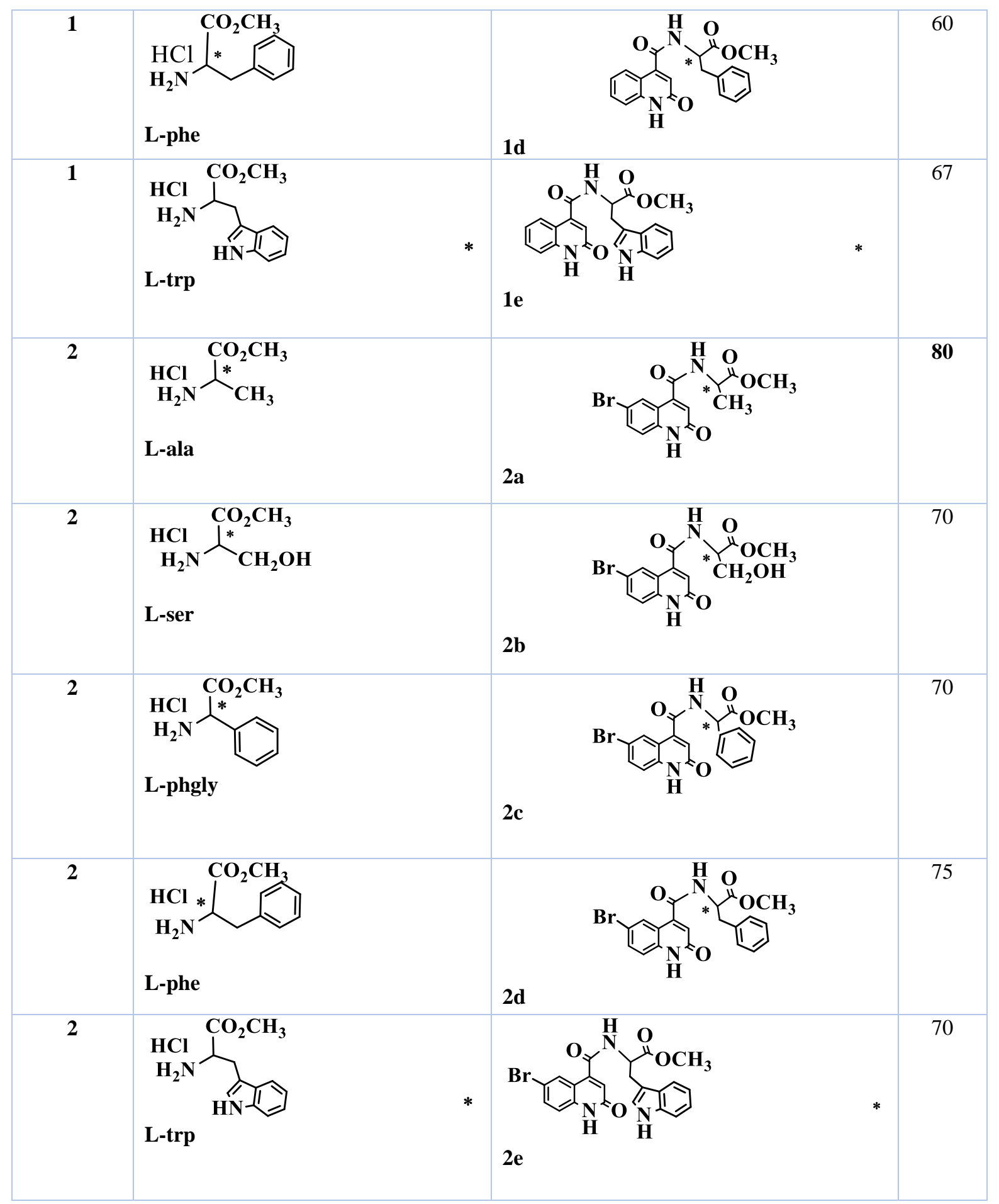

\subsection{Antibacterial activity}

The antibacterial activity of the all synthesized compounds was tested on nine type of bacteria strains: Gram $^{+}$, such as, Listeria monocytogenes, Staphylococus aureus, Enterococcus feacalis and Gram $^{-}$such as: Salmonella sp, Enterobacter sp, Klebsiella pneumonia, Acinetobacter baumannii, Escherichia coli, Haemophilus influenza, using a Muller-Hinton medium. The preliminary study concerned the antibacterial screening of all synthesized compounds using the disc diffusion method. The second step has been oriented towards the minimum inhibitory concentration values (MIC) of the compounds that showed important diffusion diameters.

Both compounds $\mathbf{1 a}$ and $\mathbf{2}$ showed an antibacterial activity against bacterium Escherichia coli and bacterium Enterococsus feacium, respectively, with the highest diameter of inhibition zones $(\mathrm{d}=14 \mathrm{~mm})$. However, Listeria monocytogenes and Klebsiella pneumonia strains showed resistance for all the synthesized compounds, no interesting inhibition zones were observed (Figure 2). 

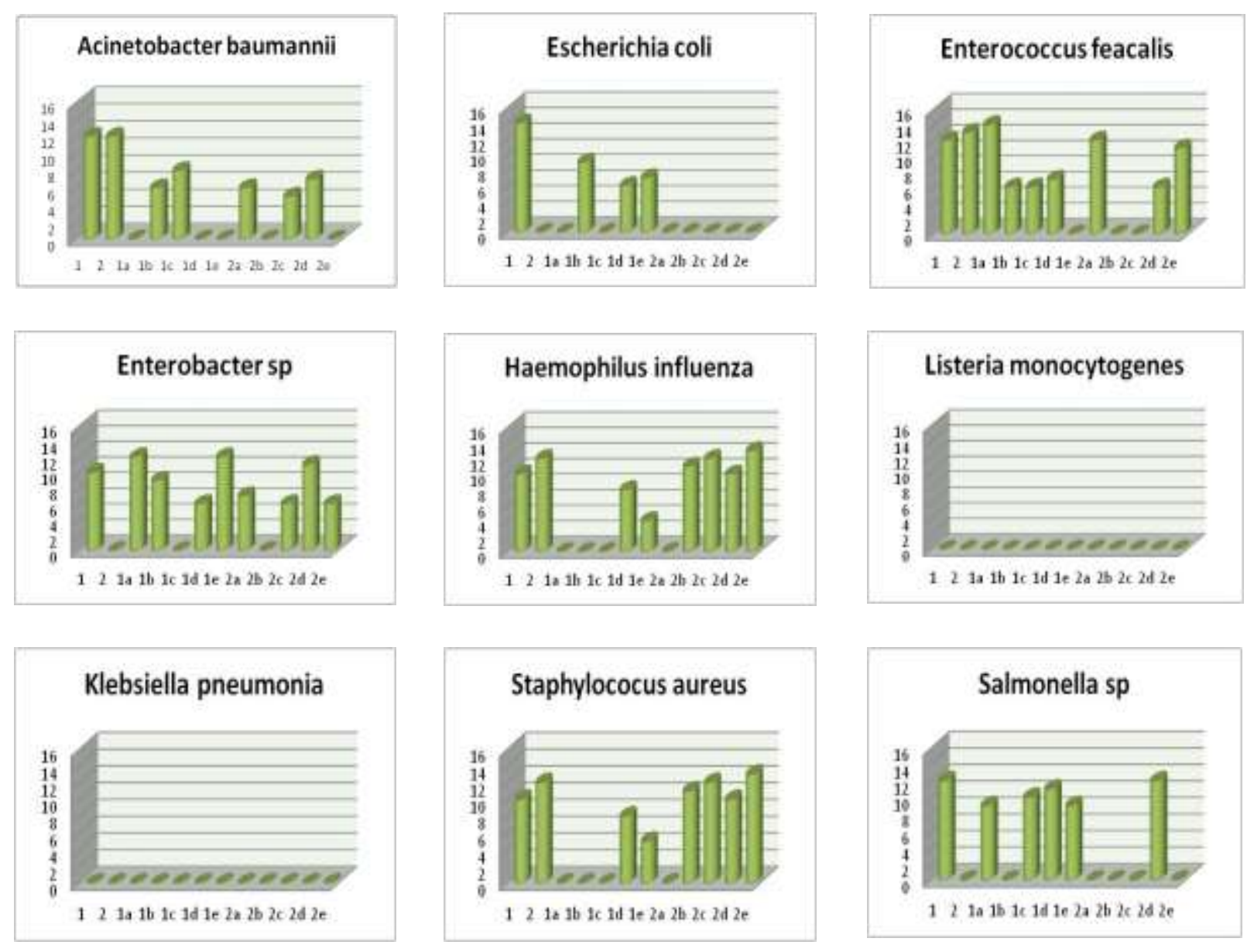

Figure 2. Inhibition diameters data of the synthesized products against Listeria monocytogenes, Salmonella $s p$, Staphylococus aureus, Enterobacter sp, Enterococcus feacalis, Klebsiella pneumonia, Acinetobacter baumannii, Escherichia coli, Haemophilus influenza.

In order to test the sensibility of bacterial strains, an antibiotic susceptibility test was performed on eight different types of antibiotics: erythromycin, ofloxacin, ticarcillin, oxacillin, ampicillin, norfloxacin, ceftazidim, cefotaxim. The results showed that all bacterial strains tested present some resistance to the antibiotics, mainly in the case of the bacteria: Acinetobacter baumannii, Escherichia coli and Listeria monocytogenes, as for the following four antibiotics: erythromycin, oxacillin, ticarcillin and ceftazidim. The manifested character was shown at certain bacterial strains without presenting any sensibility for all the strains tested or without matching with those of strains types. The sensibility was very marked for ofloxacin (fluoroquinolone antibiotic family) affecting the following strains Staphylococcus aureus, Klebsiella pneumonia, Haemophilus influenza, and Enterococcus feacalis, as well as, for norfloxacin against bacteria Klebsiella pneumonia, Enterococcus feacalis, Enterobacter sp and Salmonella sp. While in the case of ceftazidim antibiotic, only two strains present some sensitivity towards Klebsiella pneumonia and Salmonella sp, followed by ampicillin towards Salmonella $s p$. Finally, the most sensitive bacterial strains affected both Klebsiella pneumonia and Salmonella sp followed by Enterococcus feacalis.

The results obtained are encouraging, showed the importance of those quinoline-carboxamides towards bacterial strains, once compared to different antibiotics; and might explain the role of bacterial strains in the acquisition of resistance against antibiotic agents. The nature of amino acid groups could influence the chemical properties of quinolinederivatives, and then modify the action modes of bacterial activities (Table 2). 
Table 2. Results of antibacterial tests on nine type of commercial antibiotics against Acinetobacter baumannii, Escherichia coli, Enterococcus feacalis, Enterobacter sp, Klebsiella pneumonia, Haemophilus influenza, Listeria Monocytogenes and Salmonella sp.

\begin{tabular}{|c|c|c|c|c|c|c|c|c|}
\hline & AMP & CAZ & CTX & $\mathrm{E}$ & NOR & OFX & $\mathrm{OX}$ & TIC \\
\hline $\begin{array}{l}\text { Acinetobacter } \\
\text { baumannii }(\mathrm{mm})\end{array}$ & $\mathbf{R}(\mathbf{6})$ & $\mathbf{R}(\mathbf{6})$ & $\mathbf{R}(6)$ & $\mathbf{R}(7)$ & R (12) & $\mathbf{R}(\mathbf{8})$ & $\mathbf{R}(\mathbf{6})$ & $\mathbf{R}(\mathbf{6})$ \\
\hline $\begin{array}{l}\text { Escherichia coli } \\
(\mathrm{mm})\end{array}$ & $\mathbf{R}(\mathbf{6})$ & $\mathbf{R}(\mathbf{6})$ & $\mathbf{R}(\mathbf{6})$ & $\mathbf{R}(\mathbf{6})$ & $\mathbf{R}(\mathbf{6})$ & $\mathbf{R}(\mathbf{6})$ & $\mathbf{R}(\mathbf{6})$ & $\mathbf{R}(\mathbf{6})$ \\
\hline $\begin{array}{l}\text { Enterococcus } \\
\text { feacalis }(\mathrm{mm})\end{array}$ & $\mathbf{R}(\mathbf{6})$ & - & - & $\mathbf{R}(\mathbf{6})$ & $S(22)$ & $S(22)$ & $\mathbf{R}(\mathbf{6})$ & $\mathbf{R}(\mathbf{6})$ \\
\hline $\begin{array}{l}\text { Enterobacter sp } \\
(\mathrm{mm})\end{array}$ & $\mathbf{R}(\mathbf{6})$ & $\mathbf{R}(\mathbf{6})$ & $\mathbf{R}(\mathbf{6})$ & - & $\mathbf{S}(\mathbf{2 0})$ & $\mathbf{R}(\mathbf{2 0})$ & $\mathbf{R}(\mathbf{6})$ & - \\
\hline $\begin{array}{l}\text { Klebsiella } \\
\text { pneumonia }(\mathrm{mm})\end{array}$ & $\mathbf{R}(\mathbf{6})$ & R (15) & $S(20)$ & $\mathbf{R}(\mathbf{6})$ & $S(25)$ & $\mathbf{S}(27)$ & $\mathbf{R}(\mathbf{6})$ & - \\
\hline $\begin{array}{l}\text { Haemophilus } \\
\text { influenza }(\mathrm{mm})\end{array}$ & $\mathbf{R}(\mathbf{6})$ & - & - & $\mathbf{R}(\mathbf{6})$ & $\mathbf{R}(\mathbf{1 5})$ & $S(28)$ & $\mathbf{R}(\mathbf{6})$ & - \\
\hline $\begin{array}{l}\text { Listeria } \\
\text { monocytogenes } \\
(\mathrm{mm})\end{array}$ & $\mathbf{R}(\mathbf{6})$ & - & - & $R(6)$ & - & - & $\mathbf{R}(\mathbf{6})$ & - \\
\hline $\begin{array}{l}\text { Staphylococcus } \\
\text { aureus }(\mathrm{mm})\end{array}$ & - & R (14) & R (18) & - & - & $S(26)$ & $\mathbf{R}(\mathbf{6})$ & - \\
\hline Salmonella sp $(\mathrm{mm})$ & $S(22)$ & - & S (20) & $\mathbf{R}(\mathbf{6})$ & S (20) & $\mathbf{R}(\mathbf{1 6})$ & $\mathbf{R}(\mathbf{6})$ & - \\
\hline
\end{tabular}

AMP: ampicillin, CAZ: ceftazidim, CTX: cefotaxim, E: erythromycin, NOR: norfloxacin, OFX: ofloxacin, OX: oxacillin, TIC: ticarcillin. R: Resistant, S: Sensitive, - : antibiotic does not match this strain. ( ): antibiotics diameter.

The in vitro minimum inhibitory concentration (MIC) values of antibacterial activities of tested compounds were determined and illustrated in Table 3. The two marked compounds $\mathbf{1 a}$ and $\mathbf{2}$ showed the lowest antimicrobial MIC at $0.0775 \mathrm{mg} / \mathrm{ml}$ against Enterococcus feacalis and $0.155 \mathrm{mg} / \mathrm{ml}$ against Acinetobacter baumannii, respectively, and considered as a promising molecules (pharmacophore) for antimicrobial activities test.
The antimicrobial activities were manifested in the case of all compounds against Enterococcus feacalis, Salmonella sp, Staphylococus aureus and Acinetobacter baumannii, respectively, are stronger than those against other bacterial strains. The following compounds $1 \mathrm{c}, 1 \mathrm{~d}, 2 \mathrm{~b}$ and $2 \mathrm{~d}$ presented less microbial activities against tested bacterial strains, while the products $1 \mathrm{a}, 1 \mathrm{~b}, 2 \mathrm{~b}, 4 \mathrm{~b}$ and $6 \mathrm{~b}$ showed moderate effect.

Table 3. In vitro antibacterial activities result (MIC values in mg/ml) of 12 compounds: 1, 2, 1a, 1b, 1c,1d, 1e, 2a, 2b, 2c, 2d, 2e against Listeria monocytogenes, Salmonella sp, Staphylococus aureus, Enterobacter sp, Enterococcus feacalis, Klebsiella pneumonia, Acinetobacter baumannii, Escherichia coli and Haemophilus influenza bacteria.

\begin{tabular}{|c|c|c|c|c|c|c|c|c|c|c|}
\hline $\begin{array}{c}\text { compo } \\
\text { unds }\end{array}$ & $\begin{array}{c}\text { Listeria } \\
\text { monocyto } \\
\text { genes }\end{array}$ & $\begin{array}{c}\text { Staphylo } \\
\text { cocus } \\
\text { aureus }\end{array}$ & $\begin{array}{c}\text { Enteroc } \\
\text { occus } \\
\text { feacalis }\end{array}$ & $\begin{array}{c}\text { Salmo } \\
\text { nella } \\
\text { sp }\end{array}$ & $\begin{array}{c}\text { Enterob } \\
\text { acter sp }\end{array}$ & $\begin{array}{c}\text { Klebsi } \\
\text { ella } \\
\text { pneum } \\
\text { onia }\end{array}$ & $\begin{array}{c}\text { Acinetob } \\
\text { acter } \\
\text { baumann } \\
\text { ii }\end{array}$ & $\begin{array}{c}\text { Escheri } \\
\text { chia } \\
\text { coli }\end{array}$ & $\begin{array}{c}\text { Haemop } \\
\text { hilus } \\
\text { influenz } \\
\text { a }\end{array}$ \\
\hline & \multicolumn{2}{|c|}{ Gram +} & \multicolumn{5}{|c|}{ Gram - } \\
\hline 1 & - & 2,5 & 5 & 5 & 5 & - & 5 & 2,5 & 2,5 \\
\hline 2 & - & 10 & 1,25 & - & - & - & 0,155 & - & 5 \\
\hline $1 \mathrm{a}$ & - & 10 & $\mathbf{0 , 0 7 7 5}$ & 10 & 2,5 & - & - & - & - \\
\hline $1 \mathrm{~b}$ & - & - & - & - & 5 & - & - & 10 & - \\
\hline $1 \mathrm{c}$ & - & - & - & 10 & - & - & - & - & - \\
\hline
\end{tabular}




\begin{tabular}{|c|c|c|c|c|c|c|c|c|c|}
\hline $1 d$ & - & - & - & 10 & - & - & - & - & - \\
\hline $1 \mathrm{e}$ & - & - & - & 10 & 10 & - & - & - & - \\
\hline $2 \mathrm{a}$ & - & - & 1,25 & - & - & - & - & - & - \\
\hline $2 b$ & - & - & - & - & - & - & - & - & - \\
\hline $2 c$ & - & - & - & - & - & - & - & - & 2.5 \\
\hline $2 d$ & - & 10 & - & 2.5 & 2.5 & - & - & - & 10 \\
\hline $2 \mathrm{e}$ & - & - & 0.625 & - & & - & - & - & 1.25 \\
\hline DMSO & - & - & - & - & - & - & - & - & - \\
\hline
\end{tabular}

- : Presence of growth (no MIC). DMSO: dimethyl sulfoxide as solvent.

\section{Conclusion}

In this work a series of five new compounds of 2-oxo1,2-dihyquinoline-6-carboxamides (1a, 1b, 1c, 1d and $1 \mathrm{e})$, as well as, another series of 5-bromo-2-oxo-1,2dihyquinoline-4-carboxamides containing five new corresponding components $(2 \mathrm{a}, 2 \mathrm{~b}, 2 \mathrm{c}, 2 \mathrm{~d}, 2 \mathrm{e})$ have been prepared. All synthesized products were purified by silica gel liquid column chromatography and their structures were characterized by both ${ }^{1} \mathrm{H}$ and ${ }^{13} \mathrm{C}$ NMR spectroscopy and mass spectrometry. Their antibacterial activities were evaluated against bacterial strains: $\mathrm{Gram}^{+}$, such as, Listeria monocytogenes, Staphylococus aureus and Enterococcus feacalis; and Gram, such as, Salmonella sp, Enterobacter sp, Klebsiella pneumonia, Acinetobacter baumannii, Escherichia coli and Haemophilus influenza.

The component 1a presented the highest antibacterial activity against Acinetobacter baumannii strain with the $\mathrm{MIC}=77.5 \mu \mathrm{g} / \mathrm{ml}$, while the most synthesized compounds showed moderate antibacterial activity towards nine different bacteria strains.

\section{Experimental}

\subsection{General Methods}

Reagents: Isatin 97\%, malonic Acid 99\%, sodium acetate $>99 \%$, thionyl chloride $\mathrm{SOCl}_{2} \quad 97 \%$, triethylamine $99.5 \%$, HBTU $98 \%$ and amino acids 99\% (L-alanine, L-phenylalanine, L-phenylglycine, L-Serine and L-tryptophane), were purchased from Sigma-Aldrich. Analytical solvents: acetic acid $99.5 \%$, dimethylformamide anhydrous $99.8 \%$, ethyl acetate (HPLC-grade) and hexane (HPLC-grade) were purchased from Sigma-Aldrich.

Column liquid chromatography was performed on 60 Merck silica gel (230-400 mesh ASTM). Thin layer chromatography (TLC) was performed on Merck aluminum plates coated with $60 \mathrm{~F}_{254}$ Merck silica gel (thickness $0.2 \mathrm{~mm}$ ), and the synthesized components were revealed by an ultra-violet lamp set at $254 \mathrm{~nm}$. Melting points were determined by an Electrothermal IA 9000 Series digital fusiometer using capillary tubes.
NMR spectra were performed on Bruker DRX-300 AVANCE spectrometer at the "Cité Innovation" Sidi Mohamed Ben Abellah University of Fez . ${ }^{1} \mathrm{H}$ NMR spectra were recorded at $300 \mathrm{MHz}$, and ${ }^{13} \mathrm{C} \mathrm{NMR}$ spectra were recorded at $75 \mathrm{MHz}$. Samples were dissolved in DMSO- $\mathrm{d}_{6}$ or/in $\mathrm{CDCl}_{3}$. The chemical shift of different peaks was expressed in ppm, and the coupling constants ${ }^{n} \mathbf{J}$ in $\mathrm{Hz}$. For describing the multiplicity of signals, the following abbreviations have been used: s: singlet, d: doublet, dd: doublet doublet, ddd: doublet doublet doublet, m: multiplet, t: triplet, q: quadruplet.

The high resolution mass spectra (HRMS) were registered in the $\mathrm{EI}(70 \mathrm{eV})$ or FAB mode and were reported as $\mathrm{m} / \mathrm{z}$ (\% of relative intensity) at the mass spectrometry service of the University of Valencia, Spain.

\section{Synthesis of 2-oxo-1,2-dihydroquinoline-4- carboxylic acid 1}

A mixture of isatin $(0.013 \mathrm{~mol})$, malonic acid $(0.016$ $\mathrm{mol})$ and sodium acetate $(1.9 \mathrm{mmol})$ dissolved in acetic acid solvent medium and heated under reflux during 24 hours. After cooling at room temperature, a quantity of water was added until precipitation formed, which will be filtered afterward.

Synthesis of 6-bromo-2-oxo-1,2-dihydroquinoline-4carboxylic acid 2.

A mixture of 5-bromo isatin $(0.013 \mathrm{~mol})$, malonic acid $(0.016 \mathrm{~mol})$ and sodium acetate $(1.9 \mathrm{mmol})$ dissolved in acetic acid. Medium stirred and heated under reflux for 24 hours. The water was added to the mixture until formation of precipitate and then filtered.

\section{General procedure for the protection of carboxylic acids groups derived from amino acids}

An amount of $\mathrm{SOCl}_{2}(2 \mathrm{~mol})$ was added drop by drop to the methanol $(\mathrm{MeOH})$ at $0{ }^{\circ} \mathrm{C}$. After $15 \mathrm{~min}$, the mixture was added to the amino acid (1 mol), stirred during 2 hours at room temperature and then heated under reflux for 2 hours. The excess of unreacted mixture of $\mathrm{MeOH}$ and $\mathrm{SOCl}_{2}$ was removed using rotary evaporator. The remaining residue has been solubilized in $\mathrm{MeOH}$ and then an amount of diethyl ether was added until precipitation, followed by filtration. 
General procedure for the preparation of 2-oxo1,2-dihydroquinoline-4-carboxamides 1a-1e

A mixture of 2-oxo-1,2-dihydroquinoline-4carboxylic acid (1 mol), amino acid (1.5 mol), hexafluorophosphate benzotriazole tetramethyl uronium HBTU $(1.1 \mathrm{~mol})$ solubilized in $20 \mathrm{ml}$ of DMF, and then $3.3 \mathrm{~mol}$ of triethylamine (TEA) was added in small amounts at $0{ }^{\circ} \mathrm{C}$. After $20 \mathrm{~min}$, the reaction is abandoned at room temperature during 12 hours.

General Procedure for the preparation of 6bromo-2-oxo-1,2-dihydroquinoline-4-

carboxamides, $2 \mathrm{a}-2 \mathrm{e}$

A mixture of 6-bromo-2-oxo-1,2-dihydroquinoline-4carboxylic acid $(1 \mathrm{~mol})$, amino acid $(1.5 \mathrm{~mol})$ and HBTU (1.1 mol) in $20 \mathrm{ml}$ of dimethylformamide (DMF), and then $3.3 \mathrm{~mol}$ of triethylamine (TEA) is added in small amount at $0{ }^{\circ} \mathrm{C}$. After $20 \mathrm{~min}$, the reaction was abandoned at room temperature during 12 hours.

\subsection{Disc diffusion method}

The disc diffusion method ${ }^{33}$ started by seeding the bacterial strains on the surface of Mueller Hinton agar. After $15 \mathrm{~min}$ the sterile wattman $\mathrm{N}^{\circ} 1$ disc (diameter of $6 \mathrm{~mm}$ ) is placed on the surface each agar and impregnated $10 \mu \mathrm{l}$ of compounds 1-2e (10 $\mathrm{mg} / 1 \mathrm{ml}$ of DMSO). Then petri dishes were incubated at $37{ }^{\circ} \mathrm{C}$ during 24 hours. After incubation, the absence of bacterial growth expressing antimicrobial activity by the presence of a translucent halo around the disc including a diameter measured with a caliper in $\mathrm{mm}$.

\subsection{Minimum inhibitory concentration (MIC)}

The minimum inhibitory concentrations of the synthesized compounds were determined and based on the literature data by the method of Bouhdid et al. ${ }^{34}$ with some modification. The product was serially diluted in DMSO and the Brain Heart Infusion (BHI) nutrient agar has been sterilized. $140 \mu \mathrm{l}$ of the sterilized medium was added to all microplate wells using the microdilution method, containing $20 \mu \mathrm{l}$ DMSO and a series of test product dilutions ranging from $10 \mathrm{mg} / \mathrm{ml}$ to $0.0025 \mathrm{mg} / \mathrm{ml}$. Then, $20 \mu \mathrm{L}$ of bacterial inoculum was added to each well. The $12^{\text {th }}$ well was considered as growth control. The microplate was incubated at $37{ }^{\circ} \mathrm{C}$ during 24 hours and $10 \mu \mathrm{L}$ of triphenyltetrazolium (TTC) chloride was added to each well as a growth indicator. After $2 \mathrm{~h}$ in incubation at $37^{\circ} \mathrm{C}$ the $\mathrm{MIC}$ is the lowest concentration that does not cause any change in TCC staining and corresponds to the absence of bacterial growth.

\subsection{Characterization}

Compound 1: 2-oxo-1,2-dihydroquinoline-4-

carboxylic acid

Gray solid, $\mathrm{mp}=280^{\circ} \mathrm{C}$.

NMR ${ }^{1} \mathrm{H} \delta$ (ppm) $300 \mathrm{MHz}$, DMSO-d 6 : 13.9 (s, broad, $1 \mathrm{H}, \mathrm{OH}), 12.17$ (s, 1H, $\mathrm{NH}_{\text {quinoline }}$ ), 8.15 $\left(\mathrm{dd}, 1 \mathrm{H},{ }^{3} \mathrm{~J}_{\mathrm{H}-\mathrm{H}}=8.1 \mathrm{HZ},{ }^{4} \mathrm{~J}_{\mathrm{H}-\mathrm{H}}=1.12 \mathrm{~Hz}, \mathrm{H}_{5}\right), 7.63(\mathrm{td}$, $\left.1 \mathrm{H},{ }^{3} \mathrm{~J}_{\mathrm{H}-\mathrm{H}}=8.3 \mathrm{~Hz},{ }^{4} \mathrm{~J}_{\mathrm{H}-\mathrm{H}}=1.2 \mathrm{~Hz}, \mathrm{H}_{7}\right), 7.36(\mathrm{dd}, 1 \mathrm{H}$, $\left.{ }^{3} \mathbf{J}_{\mathrm{H}-\mathrm{H}}=8.3 \mathrm{~Hz}, \quad{ }^{4} \mathbf{J}_{\mathrm{H}-\mathrm{H}}=1.2 \mathrm{~Hz}, \quad \mathrm{H} 8\right), 7.23(\mathrm{td}, 1 \mathrm{H}$, $\left.{ }^{3} \mathrm{~J}_{\mathrm{H}-\mathrm{H}}=8.28 \mathrm{~Hz}, \mathrm{~J}_{\mathrm{H}-\mathrm{H}}=1.2 \mathrm{~Hz}, \quad \mathrm{H}_{6}\right), \quad 6.86 \quad(\mathrm{~s}, \quad 1 \mathrm{H}$, $\left.=\mathrm{CH}_{\text {ethylenic }}\right)$.

NMR ${ }^{13} \mathrm{C} \delta(\mathrm{ppm}) 300 \mathrm{MHz}, \mathrm{DMSO}-\mathrm{d}_{6}: 167.2(\mathrm{C}=\mathrm{O}$ acid $), 163(\mathrm{C}=\mathrm{O}$ amide quinoline $), 141.7-139.8\left(\mathrm{C}_{4 \mathrm{a}}-\mathrm{C}_{8 \mathrm{a}}\right)$,

$131.3\left(\mathrm{Ct}_{5}\right), 126.5\left(\mathrm{Ct}_{7}\right), 123.8(=\mathrm{Ct}), 120\left(\mathrm{Ct}_{6}\right)$,

$122.6\left(\mathrm{C}_{4}\right), 116.2\left(\mathrm{Ct}_{8}\right)$.

Mass Spectrometry: $[\mathrm{MH}]^{+} \mathrm{m} / \mathrm{z}=190.05$.

Compound 2 : 6-bromo-2-oxo-1,2-

dihydroquinoline-4-carboxylic acid

Gray solid, $\mathrm{mp}=285^{\circ} \mathrm{C}$.

NMR ${ }^{1} \mathrm{H} \delta(\mathrm{ppm}) 300 \mathrm{MHz}, \mathrm{DMSO}-\mathrm{d}_{6}$ : 14.05 (s, broad, $\left.{ }^{1} \mathrm{H}, \mathrm{OH}\right), 12.22\left(\mathrm{~s}, 1 \mathrm{H}, \mathrm{NH}_{\text {quinoline }}\right), 8.42(\mathrm{~d}, 1 \mathrm{H}$, $\left.{ }^{4} \mathbf{J}_{\mathrm{H}-\mathrm{H}}=1.8 \mathrm{~Hz}, \mathrm{H}_{5}\right), \quad 7.7 \quad\left(\mathrm{dd}, \quad 1 \mathrm{H}, \quad{ }^{3} \mathbf{J}_{\mathrm{H}-\mathrm{H}}=9 \mathrm{~Hz}, \quad{ }^{4} \mathbf{J}_{\mathrm{H}-}\right.$ $\left.\mathrm{H}=1.8 \mathrm{~Hz}, \mathrm{H}_{7}\right), 7.30\left(\mathrm{~d}, 1 \mathrm{H},{ }^{3} \mathrm{~J}_{\mathrm{H}-\mathrm{H}}=9 \mathrm{~Hz}, \mathrm{H}_{8}\right), 6.98(\mathrm{~s}, 1 \mathrm{H}$, $\mathrm{CH}_{\text {ethylenic }}$ ).

RMN ${ }^{13} \mathrm{C} \quad \delta$ (ppm) $300 \mathrm{MHz}$, DMSO-d 6 : 166.7 $\left(\mathrm{C}=\mathrm{O}_{\text {acide }}\right), 161.2\left(\mathrm{C}=\mathrm{O}_{\text {amide }}\right), 139.6-139.0 \quad\left(\mathrm{C}_{4 \mathrm{a}}-\mathrm{C}_{8 \mathrm{a}}\right)$, $133.8\left(\mathrm{Ct}_{5}\right), 128.7\left(\mathrm{Ct}_{7}\right), 125.9\left(\mathrm{Ct}_{\text {ethylenic }}\right), 117.9\left(\mathrm{C}_{4}\right)$, $114.5\left(\mathrm{Ct}_{8}\right)$.

Mass Spectrometry: $[\mathrm{MH}]^{+} \mathrm{m} / \mathrm{z}=268, \mathrm{~m} / \mathrm{z}=270$

$(\mathrm{M}+2)$.

Compound 1a: methyl (2-oxo-1.2-dihydroquinoline4-yl)- $L$-alaninate

white solid, $\mathrm{mp}=247^{\circ} \mathrm{C}$.

NMR ${ }^{1} \mathrm{H} \delta$ (ppm) $300 \mathrm{MHz}, \mathrm{DMSO}-\mathrm{d}_{6}: 11.94$ (s, $1 \mathrm{H}$, $\left.\mathrm{NH}_{\text {quinoline }}\right), 9.17\left(\mathrm{~s}, 1 \mathrm{H},{ }^{3} \mathrm{~J}_{\mathrm{H}-\mathrm{H}}=6.9 \mathrm{~Hz}, \mathrm{NH}\right), 7.75-7.21$ $\left.\left(\mathrm{m}, 4 \mathrm{H}, \mathrm{H}_{\mathrm{ar}}\right)\right), 6.50\left(\mathrm{~s}, 1 \mathrm{H}, \mathrm{CH}_{\text {ethylenic }}\right), 4.69(\mathrm{qd}, 1 \mathrm{H}$, $\left.{ }^{3} \mathrm{~J}_{\mathrm{H}-\mathrm{H}}=7.2 \mathrm{~Hz},{ }^{3} \mathrm{~J}_{\mathrm{H}-\mathrm{H}}=6.9 \mathrm{~Hz}, * \mathrm{CH}-\mathrm{N}\right), 3.67\left(\mathrm{~s}, 3 \mathrm{H}, \mathrm{CH}_{3}-\right.$ $\mathrm{O}), 1.48\left(\mathrm{~d}, 3 \mathrm{H}, \mathrm{CH}_{3}\right)$.

NMR ${ }^{13} \mathrm{C} \delta(\mathrm{ppm}) 300 \mathrm{MHz}$, DMSO-d 6 : 173.19 $\left(\mathrm{C}=\mathrm{O}_{\text {amide }}\right), 163\left(\mathrm{C}=\mathrm{O}_{\text {amide quinoline }}\right), 161.70\left(\mathrm{C}=\mathrm{O}_{\text {ester }}\right)$, 146.29-139.65 $\left(\mathrm{C}_{4 \mathrm{a}}-\mathrm{C}_{8 \mathrm{a}}\right), 131.37\left(\mathrm{Ct}_{5}\right), 126.39\left(\mathrm{Ct}_{7}\right)$, 122.67 (=Ct tethylenic), $122.42\left(\mathrm{C}_{4}\right), 120\left(\mathrm{Ct}_{6}\right), 116.1$ $\left(\mathrm{Ct}_{8}\right), 52.62(* \mathrm{CH}-\mathrm{N}), 48.5\left(\mathrm{CH}_{3}-\mathrm{O}\right), 16.6\left(\mathrm{CH}_{3}\right)$.

Mass Spectrometry: $[\mathrm{MH}]^{+} \mathrm{m} / \mathrm{z}=275.10$, $\mathrm{m} / \mathrm{z}=276.10(\mathrm{M}+1)$

Compound 1b: methyl (2-oxo-1.2-dihydroquinoline4-yl)-L-serinate

White solid, $\mathrm{mp}=211^{\circ} \mathrm{C}$.

NMR ${ }^{1} \mathrm{H} \delta$ (ppm) $300 \mathrm{MHz}$, DMSO-d 6 : 11.94 (s, $1 \mathrm{H}$, $\left.\mathrm{NH}_{\text {quinoline }}\right), 9.17\left(\mathrm{~s}, 1 \mathrm{H},{ }^{3} \mathrm{~J}_{\mathrm{H}-\mathrm{H}}=6.9 \mathrm{~Hz}, \mathrm{NH}\right), 7.75-7.21$ $\left(\mathrm{m}, 4 \mathrm{H}, \mathrm{H}_{\mathrm{ar}}\right), 6.50\left(\mathrm{~s}, 1 \mathrm{H}, \mathrm{CH}_{\text {ethylenic }}\right), 4.69\left(\mathrm{dd}, 1 \mathrm{H},{ }^{3} \mathrm{~J}_{\mathrm{H}-}\right.$ $\left.\mathrm{H}=9 \mathrm{~Hz},{ }^{3} \mathrm{~J}_{\mathrm{H}-\mathrm{H}}=6.9 \mathrm{~Hz}, * \mathrm{CH}-\mathrm{N}\right), 3.8\left(\mathrm{~d}, 2 \mathrm{H},{ }^{3} \mathrm{~J}_{\mathrm{H}-\mathrm{H}}=9 \mathrm{~Hz}\right.$, $\left.\mathrm{CH}_{2}-\mathrm{OH}\right), 3.4$ (s, $\left.3 \mathrm{H}, \mathrm{CH}_{3}-\mathrm{O}\right)$.

NMR ${ }^{13} \mathrm{C} \delta(\mathrm{ppm}) 300 \mathrm{MHz}, \mathrm{DMSO}-\mathrm{d}_{6}$ : 171.01 $\left(\mathrm{C}=\mathrm{O}_{\text {amide }}\right), \quad 166.65 \quad\left(\mathrm{C}=\mathrm{O}_{\text {amide }}\right.$ quinoline $), \quad 161.70$ $\left(\mathrm{C}=\mathrm{O}_{\text {ester }}\right), \quad 146.29-139.65 \quad\left(\mathrm{C}_{4 \mathrm{a}}-\mathrm{C}_{8 \mathrm{a}}\right), 131.32 \quad\left(\mathrm{Ct}_{5}\right)$, $126.39\left(\mathrm{Ct}_{7}\right), 122.42$ (=Ct $\left.\mathrm{Ct}_{\text {ethylenic }}\right), 122.42\left(\mathrm{C}_{4}\right), 120.42$ $\left(\mathrm{Ct}_{6}\right), 116.70\left(\mathrm{Ct}_{8}\right), 61.3\left(\mathrm{CH}_{2}-\mathrm{O}\right), 55.77\left({ }^{*} \mathrm{CH}-\mathrm{N}\right)$, $53.06\left(\mathrm{CH}_{3}-\mathrm{O}\right)$.

Mass Spectrometry: $[\mathrm{MH}]^{+} \mathrm{m} / \mathrm{z}=291.10$, $\mathrm{m} / \mathrm{z}=292.10(\mathrm{M}+1)$.

Compound 1c: methyl (2-oxo-1.2-dihydroquinoline4-yl)-L-phenylglycinate

White solide, $\mathrm{mp}=211^{\circ} \mathrm{C}$.

NMR ${ }^{1} \mathrm{H} \delta$ (ppm) $300 \mathrm{MHz}$, DMSO-d 6 : 11.94 (s, $1 \mathrm{H}$, $\left.\mathrm{NH}_{\text {quinoline }}\right), 9.66\left(\mathrm{~s}, 1 \mathrm{H},{ }^{3} \mathrm{~J}_{\mathrm{H}-\mathrm{H}}=5.61 \mathrm{~Hz}, \mathrm{NH}\right), 7.9-7$ 
$\left(\mathrm{m}, 9 \mathrm{H}, \mathrm{H}_{\mathrm{ar}}\right), 6.4\left(\mathrm{~s}, 1 \mathrm{H}, \mathrm{CH}_{\text {ethylenic }}\right), 4.69\left(\mathrm{~d}, 1 \mathrm{H},{ }^{3} \mathrm{~J}_{\mathrm{H}-}\right.$ $\mathrm{H}=5.61 \mathrm{~Hz}, * \mathrm{CH}-\mathrm{N}), 3.71\left(\mathrm{~s}, 3 \mathrm{H}, \mathrm{CH}_{3}-\mathrm{O}\right)$.

NMR ${ }^{13} \mathrm{C} \delta(\mathrm{ppm}) 300 \mathrm{MHz}, \mathrm{DMSO}-\mathrm{d}_{6}: 172.09$ $\left(\mathrm{C}=\mathrm{O}_{\text {amide }}\right), \quad 166.25 \quad\left(\mathrm{C}=\mathrm{O}_{\text {amide }}\right.$ quinoline $), \quad 161.54$ $\left(\mathrm{C}=\mathrm{O}_{\text {ester }}\right), \quad 146.29-139.65 \quad\left(\mathrm{C}_{4 \mathrm{a}}-\mathrm{C}_{8 \mathrm{a}}\right), 137.76 \quad\left(\mathrm{Cq}_{\mathrm{ar}}\right.$ phenyl $), 131.36\left(\mathrm{Ct}_{5}\right), 129.15\left(\mathrm{Ct}_{\mathrm{ar} \text { phenyl }}\right), 128.92\left(\mathrm{Ct}_{\mathrm{ar}}\right.$ phenyl $), 128.63\left(\mathrm{Ct}_{\mathrm{ar}}\right.$ phenyl $), 127.06\left(\mathrm{Ct}_{7}\right), 122.43$ (=Ct tethylenic $), 122.42\left(\mathrm{C}_{4}\right), 120.42\left(\mathrm{Ct}_{6}\right), 116.38(\mathrm{Cq}$ ethylenic $), 116.00\left(\mathrm{Ct}_{8}\right), 52.94(* \mathrm{CH}-\mathrm{N}), 47.96\left(\mathrm{CH}_{3}-\mathrm{O}\right)$. Mass Spectrometry: $[\mathrm{MH}]^{+} \mathrm{m} / \mathrm{z}=337.11, \mathrm{~m} / \mathrm{z}=338.12$ $(\mathrm{M}+1)$

Compound 1d: methyl (2-oxo-1.2-dihydroquinoline4-yl)-L-phenylalaninate

white solide, $\mathrm{mp}=211^{\circ} \mathrm{C}$.

NMR ${ }^{1} \mathrm{H} \delta$ (ppm) $300 \mathrm{MHz}, \mathrm{DMSO}-\mathrm{d}_{6}: 11.94$ (s, $1 \mathrm{H}$, $\left.\mathrm{NH}_{\text {quinoline }}\right), 9.17\left(\mathrm{~s}, 1 \mathrm{H},{ }^{3} \mathrm{~J}_{\mathrm{H}-\mathrm{H}}=8 \mathrm{~Hz}, \mathrm{NH}\right), 7.5-7(\mathrm{~m}$, $\left.\left.9 \mathrm{H}, \mathrm{H}_{\mathrm{ar}}\right)\right), 6.25\left(\mathrm{~s}, 1 \mathrm{H}, \mathrm{CH}_{\text {ethylenic }}\right), 4.69\left(\mathrm{ddd}, 1 \mathrm{H},{ }^{3} \mathrm{~J}_{\mathrm{H}-}\right.$ $\left.\mathrm{H}=8 \mathrm{~Hz},{ }^{3} \mathrm{~J}_{\mathrm{H}-\mathrm{H}}=10.8 \mathrm{~Hz},{ }^{3} \mathrm{~J}_{\mathrm{H}-\mathrm{H}}=4.8 \mathrm{~Hz}, * \mathrm{CH}-\mathrm{N}\right), 3.71(\mathrm{~s}$, $\left.3 \mathrm{H}, \mathrm{CH}_{3}-\mathrm{O}\right), 3.19\left(\mathrm{dd}, 1 \mathrm{H},{ }^{3} \mathrm{~J}_{\mathrm{H}-\mathrm{H}}=4.8 \mathrm{~Hz},{ }^{2} \mathrm{~J}_{\mathrm{H}-\mathrm{H}}=\right.$ $\left.13.8 \mathrm{~Hz}, \mathrm{CH}_{2}-\mathrm{Ar}\right), 3.0\left(\mathrm{dd}, 1 \mathrm{H},{ }^{3} \mathrm{~J}_{\mathrm{H}-\mathrm{H}}=10.8 \mathrm{~Hz}\right.$, $\left.{ }^{2} \mathrm{~J}_{\mathrm{H}-\mathrm{H}}=13.8 \mathrm{~Hz}, \mathrm{CH}_{2}-\mathrm{Ar}\right)$.

NMR ${ }^{13} \mathrm{C} \delta$ (ppm) (300 MHz, DMSO-d 6 ): 172.09 $\left(\mathrm{C}=\mathrm{O}_{\text {amide }}\right), \quad 166.25 \quad\left(\mathrm{C}=\mathrm{O}_{\text {amide }}\right.$ quinoline $), \quad 161.54$ $\left(\mathrm{C}=\mathrm{O}_{\text {ester }}\right), \quad 146.29-139.65 \quad\left(\mathrm{C}_{4 \mathrm{a}}-\mathrm{C}_{8 \mathrm{a}}\right), 137.76 \quad\left(\mathrm{Cq}_{\mathrm{ar}}\right.$ phenyl $), 131.36\left(\mathrm{Ct}_{5}\right), 129.15\left(\mathrm{Ct}_{\mathrm{ar}}\right.$ phenyl $), 128.92\left(\mathrm{Ct}_{\mathrm{ar}}\right.$ phenyl $), 128.63\left(\mathrm{Ct}_{\mathrm{ar}}\right.$ phenyl $), 127.06\left(\mathrm{Ct}_{7}\right), 122.43$ (=Ct thylenic), $122.42\left(\mathrm{C}_{4}\right), 120.42\left(\mathrm{Ct}_{6}\right), 116.38(\mathrm{Cq}$ phenyl $), 116.00\left(\mathrm{Ct}_{8}\right), 53.98\left(\mathrm{CH}_{2}-\mathrm{Ar}\right), 52.67\left({ }^{*} \mathrm{CH}-\mathrm{N}\right)$, $53.06\left(\mathrm{CH}_{3}-\mathrm{O}\right)$.

Mass Spectrometry: $[\mathrm{MH}]^{+} \mathrm{m} / \mathrm{z}=351.13$, $\mathrm{m} / \mathrm{z}=352.13(\mathrm{M}+1)$.

Compound 1e: methyl (2-oxo-1.2-dihydroquinoline4-yl)-L-tryptophanate

Grey solide, $\mathrm{mp}=211^{\circ} \mathrm{C}$.

NMR $1 \mathrm{H} \delta(\mathrm{ppm}) 300 \mathrm{MHz}, \mathrm{DMSO}-\mathrm{d}_{6}: 11.94$ (s, 1 $\left.\mathrm{H}, \mathrm{NH}_{\text {quinoline }}\right), 10.94\left(\mathrm{~s}, 1 \mathrm{H}, \mathrm{NH}_{\text {indol }}\right), 9.22\left(\mathrm{~s}, 1 \mathrm{H},{ }^{3} \mathrm{~J}_{\mathrm{H}-}\right.$ $\mathrm{H}=7.5 \mathrm{~Hz}, \mathrm{NH}), 7.5-7\left(\mathrm{~m}, 9 \mathrm{H}, \mathrm{H}_{\mathrm{ar}}+\mathrm{H}_{\mathrm{indol}}\right), 6.4(\mathrm{~s}, 1 \mathrm{H}$, $\mathrm{CH}_{\text {ethylenic }}$ ), 4.8 (ddd, $1 \mathrm{H},{ }^{3} \mathrm{~J}_{\mathrm{H}-\mathrm{H}}=9.6 \mathrm{~Hz},{ }^{3} \mathrm{~J}_{\mathrm{H}-\mathrm{H}}=5.1 \mathrm{~Hz}$,

$\left.{ }^{3} \mathrm{~J}_{\mathrm{H}-\mathrm{H}}=7.5 \mathrm{~Hz} * \mathrm{CH}-\mathrm{N}\right), 3.71\left(\mathrm{~s}, 3 \mathrm{H}, \mathrm{CH}_{3}-\mathrm{O}\right), 3.2(\mathrm{dd}$, $1 \mathrm{H},{ }^{3} \mathrm{~J}_{\mathrm{H}-\mathrm{H}}=5.1 \mathrm{~Hz},{ }^{2} \mathrm{~J}_{\mathrm{H}-\mathrm{H}}=14.4 \mathrm{~Hz}, \mathrm{CH}_{2}$-Indo $), 3$ (dd, $1 \mathrm{H},{ }^{3} \mathrm{~J}_{\mathrm{H}-\mathrm{H}}=9.6 \mathrm{~Hz},{ }^{2} \mathrm{~J}_{\mathrm{H}-\mathrm{H}}=14.4 \mathrm{~Hz}, \mathrm{CH}_{2}$-Indol $)$.

NMR ${ }^{13} \mathrm{C} \delta(\mathrm{ppm}) 300 \mathrm{MHz}$, DMSO-d 6 : 172.45 $\left(\mathrm{C}=\mathrm{O}_{\text {amide }}\right), \quad 166.44 \quad\left(\mathrm{C}=\mathrm{O}_{\text {amide }}\right.$ quinoline $), \quad 161.64$ $\left(\mathrm{C}=\mathrm{O}_{\text {ester }}\right), \quad 146.29-139.65 \quad\left(\mathrm{C}_{4 \mathrm{a}}-\mathrm{C}_{8 \mathrm{a}}\right), 136.67 \quad\left(\mathrm{Cq}_{\mathrm{ar}}\right.$ tryptophan $), 131\left(\mathrm{Ct}_{5}\right), 127.50\left(\mathrm{Cq}_{\text {tryptophan }}\right), 126.26\left(\mathrm{Ct}_{7}\right)$, $124.33\left(\mathrm{Ct}_{\mathrm{ar}}\right.$ tryptophan $), 122.44\left(\mathrm{Ct}_{\mathrm{ar}}\right.$ tryptophan $), 121.53$ (=Ct thylenic $), 120.12\left(\mathrm{C}_{4}\right), 118.95\left(\mathrm{Ct}_{6}\right), 118.95\left(\mathrm{Ct}_{\mathrm{ar}}\right.$ tryptophan $), 118.54\left(\mathrm{Ct}_{\mathrm{ar}}\right.$ tryptophan $), 116.55(\mathrm{Cq}$ ehtylenic $)$ $116.04\left(\mathrm{Ct}_{8}\right), 111.98$ (= $\left.\mathrm{Ct}_{\text {ethylenic tryptophan }}\right), 110.04$ $\left(=\mathrm{Cq}_{\text {ethylenic tryptophan }}\right), 53.80(* \mathrm{CH}-\mathrm{N}), 52.60\left(\mathrm{CH}_{3}-\mathrm{O}\right)$, $27.05\left(\mathrm{CH}_{2}\right.$-Indol $)$.

Mass Spectrometry: $[\mathrm{MH}]^{+} \mathrm{m} / \mathrm{z}=390.14$, $\mathrm{m} / \mathrm{z}=391.14(\mathrm{M}+1)$.

Compound 2a: methyl (6-bromo-2-oxo-1.2dihydroquinoline-4-yl)-L-alininate

White solid, $\mathrm{mp}=290^{\circ} \mathrm{C}$.

NMR ${ }^{1} \mathrm{H} \delta$ (ppm) $300 \mathrm{MHz}$, DMSO-d $6: 12.1$ (s, $1 \mathrm{H}$, $\left.\mathrm{NH}_{\text {quinoline }}\right), 9.17\left(\mathrm{~s}, 1 \mathrm{H},{ }^{3} \mathrm{~J}_{\mathrm{H}-\mathrm{H}}=6.9 \mathrm{~Hz}, \mathrm{NH}\right), 7.7-7.4$ $\left(\mathrm{m}, 3 \mathrm{H}, \mathrm{H}_{\mathrm{ar}}\right), 6.36\left(\mathrm{~s}, 1 \mathrm{H}, \mathrm{CH}_{\text {ethylenic }}\right), 4.5(\mathrm{qd}, 1 \mathrm{H}$, $\left.{ }^{3} \mathbf{J}_{\mathrm{H}-\mathrm{H}}=7.5 \mathrm{~Hz},{ }^{3} \mathrm{~J}_{\mathrm{H}-\mathrm{H}}=6.9 \mathrm{~Hz}, * \mathrm{CH}-\mathrm{N}\right), 3.73(\mathrm{~s}, 3 \mathrm{H}$, $\left.\mathrm{CH}_{3}-\mathrm{O}\right), 1.40\left(\mathrm{~d}, 3 \mathrm{H},{ }^{3} \mathrm{~J}_{\mathrm{H}-\mathrm{H}}=6.9 \mathrm{~Hz}, \mathrm{CH}_{3}\right)$.

NMR ${ }^{13} \mathrm{C} \delta$ (ppm) $300 \mathrm{MHz}$, DMSO-d 6 : 173.09 $\left(\mathrm{C}=\mathrm{O}_{\text {amide }}\right), \quad 168.81 \quad\left(\mathrm{C}=\mathrm{O}_{\text {amide }} \quad\right.$ quinoline $), \quad 161.37$ $\left(\mathrm{C}=\mathrm{O}_{\text {ester }}\right), 144.88-137\left(\mathrm{C}_{4 \mathrm{a}}-\mathrm{C}_{8 \mathrm{a}}\right), 133.98\left(\mathrm{Ct}_{5}\right), 128.42$ $\left(\mathrm{Ct}_{7}\right), \quad 121.62 \quad\left(\mathrm{Ct}_{6}\right), \quad 118.31 \quad\left(=\mathrm{Ct}_{\text {ethylenic }}\right), 118.21$ (Cqethylique), $114.30\left(\mathrm{Cq}_{\mathrm{ar}}\right), 57.51(* \mathrm{CH}-\mathrm{N}), 52.31$ $\left(\mathrm{CH}_{3}-\mathrm{O}\right), 18.6\left(\mathrm{CH}_{3}\right)$.

Mass Spectrometry: $[\mathrm{MH}]^{+} \mathrm{m} / \mathrm{z}=353, \mathrm{~m} / \mathrm{z}=355$ $(\mathrm{M}+2)$.

Compound 2b: methyl (6-bromo-2-oxo-1.2dihydroquinoline-4-yl)-L-serinate

White solid, $\mathrm{mp}=211^{\circ} \mathrm{C}$.

NMR ${ }^{1} \mathrm{H} \delta$ (ppm) $300 \mathrm{MHz}$, DMSO-d $6: 12.1$ (s, $1 \mathrm{H}$, $\left.\mathrm{NH}_{\text {quinoline }}\right), 9.17\left(\mathrm{~s}, 1 \mathrm{H},{ }^{3} \mathrm{~J}_{\mathrm{H}-\mathrm{H}}=8 \mathrm{~Hz}, \mathrm{NH}\right), 7.7-7.4(\mathrm{~m}$, $\left.3 \mathrm{H}, \mathrm{H}_{\mathrm{ar}}\right), 6.36\left(\mathrm{~s}, 1 \mathrm{H}, \mathrm{CH}_{\text {ethylenic }}\right), 5.64\left(\mathrm{td}, 1 \mathrm{H},{ }^{3} \mathrm{~J}_{\mathrm{H}-\mathrm{H}}=\right.$ $\left.7.6 \mathrm{~Hz},{ }^{3} \mathrm{~J}_{\mathrm{H}-\mathrm{H}}=8 \mathrm{~Hz}, * \mathrm{CH}-\mathrm{N}\right), 3.8\left(\mathrm{~d}, 2 \mathrm{H},{ }^{3} \mathrm{~J}_{\mathrm{H}-\mathrm{H}}=7.6 \mathrm{~Hz}\right.$, $\left.\mathrm{CH}_{2}-\mathrm{OH}\right), 3.7$ (s, $\left.3 \mathrm{H}, \mathrm{CH}_{3}-\mathrm{O}\right)$.

NMR ${ }^{13} \mathrm{C} \delta(\mathrm{ppm}) 300 \mathrm{MHz}$, DMSO-d 6 : 173.09 $\left(\mathrm{C}=\mathrm{O}_{\text {amide }}\right), \quad 168.81 \quad\left(\mathrm{C}=\mathrm{O}_{\text {amide }} \quad\right.$ quinoline $), \quad 161.37$ $\left(\mathrm{C}=\mathrm{O}_{\text {ester }}\right), 144.88-137\left(\mathrm{C}_{4 \mathrm{a}}-\mathrm{C}_{8 \mathrm{a}}\right), 133.98\left(\mathrm{Ct}_{5}\right), 128.42$ $\left(\mathrm{Ct}_{7}\right), 121.62\left(\mathrm{Ct}_{6}\right), \quad 118.31 \quad\left(=\mathrm{Ct}_{\text {ethylenic }}\right), 118.21$ $\left(\mathrm{Cq}_{\text {ethylique }}\right), 114.30\left(\mathrm{Cq}_{\mathrm{ar}}\right), \quad 61.30\left(\mathrm{CH}_{2}-\mathrm{O}\right), 57.51$ $(* \mathrm{CH}-\mathrm{N}), 52.31\left(\mathrm{CH}_{3}-\mathrm{O}\right)$.

Mass Spectrometry: $[\mathrm{MH}]^{+} \mathrm{m} / \mathrm{z}=341, \mathrm{~m} / \mathrm{z}=343$ $(\mathrm{M}+2)$.

Compound 2c: methyl (6-bromo-2-oxo-1.2-

dihydroquinoline-4-yl)-L-phenylglycinate

White solid, $\mathrm{mp}=270^{\circ} \mathrm{C}$.

NMR ${ }^{1} \mathrm{H} \delta$ (ppm) $300 \mathrm{MHz}, \mathrm{DMSO}-\mathrm{d}_{6}: 12.1$ (s, 1H, $\left.\mathrm{NH}_{\text {quinoline }}\right), 9.6\left(\mathrm{~s}, 1 \mathrm{H},{ }^{3} \mathrm{~J}_{\mathrm{H}-\mathrm{H}}=8 \mathrm{~Hz}, \mathrm{NH}\right), 7.8-7.28(\mathrm{~m}$, $\left.8 \mathrm{H}, \mathrm{H}_{\mathrm{ar}}\right), 6.58\left(\mathrm{~s}, 1 \mathrm{H}, \mathrm{CH}_{\text {ethylenic }}\right), 5.64\left(\mathrm{~d}, 1 \mathrm{H},{ }^{3} \mathrm{~J}_{\mathrm{H}-}\right.$ $\left.\mathrm{H}=8 \mathrm{~Hz},{ }^{*} \mathrm{CH}-\mathrm{N}\right), 3.71\left(\mathrm{~s}, 3 \mathrm{H}, \mathrm{CH}_{3}-\mathrm{O}\right)$.

NMR ${ }^{13} \mathrm{C} \delta(\mathrm{ppm}) 300 \mathrm{MHz}$, DMSO-d 6 : 171.95 $\left(\mathrm{C}=\mathrm{O}_{\text {amide }}\right), \quad 165.93 \quad\left(\mathrm{C}=\mathrm{O}_{\text {amide }}\right.$ quinoline $), \quad 161.61$ $\left(\mathrm{C}=\mathrm{O}_{\text {ester }}\right), 144.83-138.65 \quad\left(\mathrm{C}_{4 \mathrm{a}}-\mathrm{C}_{8 \mathrm{a}}\right), 135.65 \quad\left(\mathrm{Cq}_{\mathrm{ar}}\right)$, $133.76\left(\mathrm{Cq}_{\mathrm{ar}}\right), 130\left(\mathrm{Ct}_{5}\right), 128.80\left(\mathrm{Ct}_{7}\right), 128.33\left(\mathrm{Ct}_{\mathrm{ar}}\right.$ phenyl $), 128.24\left(\mathrm{Ct}_{\mathrm{ar} \text { phenyl }}\right), 121.37$ (= $\left.\mathrm{Ct}_{\text {ethylenic }}\right), 118.27$ $\left(\mathrm{Ct}_{\text {ar phenyl }}\right), 118.03\left(\mathrm{Cq}_{\text {ethylique }}\right), 114.47\left(\mathrm{Ct}_{6}\right), 57.31$ (*CH-N), $52.51\left(\mathrm{CH}_{3}-\mathrm{O}\right)$.

Mass Spectrometry: $[\mathrm{MH}]^{+} \mathrm{m} / \mathrm{z}=415, \mathrm{~m} / \mathrm{z}=417$ $(\mathrm{M}+2)$.

Compound 2d: methyl (6-bromo-2-oxo-1.2dihydroquinoline-4-yl)-L-phenylalaninate

white solid, $\mathrm{mp}=260^{\circ} \mathrm{C}$.

NMR ${ }^{1} \mathrm{H} \delta$ (ppm) $300 \mathrm{MHz}, \mathrm{DMSO}-\mathrm{d}_{6}: 12.1$ (s, 1H, $\left.\mathrm{NH}_{\text {quinoline }}\right), 9.6\left(\mathrm{~s}, 1 \mathrm{H},{ }^{3} \mathrm{~J}_{\mathrm{H}-\mathrm{H}}=8 \mathrm{~Hz}, \quad \mathrm{NH}\right), 7.8-7.2$ $\left(\mathrm{m}, 8 \mathrm{H}, \mathrm{H}_{\mathrm{ar}}\right), 6.36\left(\mathrm{~s}, 1 \mathrm{H}, \mathrm{CH}_{\text {ethylenic }}\right), 5.64$ (ddd, $1 \mathrm{H}$, $\left.{ }^{3} \mathrm{~J}_{\mathrm{H}-\mathrm{H}}=4.8 \mathrm{~Hz},{ }^{3} \mathrm{~J}_{\mathrm{H}-\mathrm{H}}=8 \mathrm{~Hz},{ }^{3} \mathrm{~J}_{\mathrm{H}-\mathrm{H}}=10.8 \mathrm{~Hz}, * \mathrm{CH}-\mathrm{N}\right), 3.4$ $\left(\mathrm{s}, 3 \mathrm{H}, \quad \mathrm{CH}_{3}-\mathrm{O}\right), 3.3\left(\mathrm{dd}, 1 \mathrm{H},{ }^{3} \mathrm{~J}_{\mathrm{H}-\mathrm{H}}=10.8 \mathrm{~Hz}\right.$, $\left.{ }^{2} \mathrm{~J}_{\mathrm{H}-\mathrm{H}}=13.8 \mathrm{~Hz}, \mathrm{CH}_{2}-\mathrm{Ar}\right), 3.0\left(\mathrm{dd}, 1 \mathrm{H},{ }^{3} \mathrm{~J}_{\mathrm{H}-\mathrm{H}}=4.8 \mathrm{~Hz},{ }^{2} \mathrm{~J}_{\mathrm{H}-}\right.$ $\mathrm{H}=13.8 \mathrm{~Hz}, \mathrm{CH}_{2}$-Ar).

NMR ${ }^{13} \mathrm{C} \delta(\mathrm{ppm}) 300 \mathrm{MHz}$, DMSO-d 6 : 171.95 $\left(\mathrm{C}=\mathrm{O}_{\text {amide }}\right), \quad 165.71 \quad\left(\mathrm{C}=\mathrm{O}_{\text {amide }}\right.$ quinoline $), \quad 161.25$ $\left(\mathrm{C}=\mathrm{O}_{\text {ester }}\right), \quad 144.83-138.65\left(\mathrm{C}_{4 \mathrm{a}}-\mathrm{C}_{8 \mathrm{a}}\right), \quad 138.71\left(\mathrm{Cq}_{\mathrm{ar}}\right)$, $137.69\left(\mathrm{Cq}_{\mathrm{ar}}\right), 134.04\left(\mathrm{Ct}_{5}\right), 129.57\left(\mathrm{Ct}_{7}\right), 128.75\left(\mathrm{Ct}_{\mathrm{ar}}\right.$ phenyl), 128.23 ( $\left.\mathrm{Ct}_{\text {ar phenyl }}\right), 121.37$ (=Ct $\left.\mathrm{Ct}_{\text {ethylenic }}\right), 118.30$ $\left(\mathrm{Ct}_{\text {ar phenyl }}\right), 117.94$ (Cqethylique $), 114.26\left(\mathrm{Ct}_{6}\right), 54.02$ $\left({ }^{*} \mathrm{CH}-\mathrm{N}\right), 52.31\left(\mathrm{CH}_{3}-\mathrm{O}\right), 36.63\left(\mathrm{CH}_{2}-\mathrm{Ar}\right)$. 
Mass Spectrometry: $[\mathrm{MH}]^{+} \mathrm{m} / \mathrm{z}=429, \mathrm{~m} / \mathrm{z}=431$ $(\mathrm{M}+2)$.

Compound 2e: methyl (6-bromo-2-oxo-1.2dihydroquinoline-4-yl)-L-tryptophanate White solid. $\mathrm{mp}=219^{\circ} \mathrm{C}$.

NMR ${ }^{1} \mathrm{H} \delta$ (ppm) $300 \mathrm{MHz}$, DMSO-d 6 : 12.1 (s, 1H, $\mathrm{NH}$ quinoline $), 10.91\left(\mathrm{~s}, 1 \mathrm{H}, \mathrm{NH}_{\text {tryptophane }}\right), 9.3(\mathrm{~d}, 1 \mathrm{H}$, $\left.{ }^{3} \mathrm{~J}=7.5 \mathrm{~Hz}, \mathrm{NH}\right), 7.2-6.99\left(\mathrm{~m}, 8 \mathrm{H}, \mathrm{H}_{\mathrm{ar}}\right.$ et $\left.\mathrm{H}_{\text {indol }}\right), 6.4$ $(\mathrm{CH}, \mathrm{S}), \quad 5.75\left(\mathrm{ddd}, 1 \mathrm{H},{ }^{3} \mathrm{~J}_{\mathrm{H}-\mathrm{H}}=9.6 \mathrm{~Hz},{ }^{3} \mathrm{~J}=7.5 \mathrm{~Hz},{ }^{3} \mathrm{~J}_{\mathrm{H}-}\right.$ $\left.\mathrm{H}=4.8 \mathrm{~Hz},{ }^{*} \mathrm{CH}-\mathrm{N}\right), 3.72\left(\mathrm{~s}, 3 \mathrm{H}, \mathrm{CH}_{3 \mathrm{ester}}\right), 3.2(\mathrm{dd}, 1 \mathrm{H}$, $\left.{ }^{3} \mathrm{~J}_{\mathrm{H}-\mathrm{H}}=4.8 \mathrm{~Hz},{ }^{2} \mathrm{~J}_{\mathrm{H}-\mathrm{H}}=14.7 \mathrm{~Hz}, \mathrm{CH}_{2}-\mathrm{Ar}\right), 3(\mathrm{dd}, 1 \mathrm{H}$, $\left.{ }^{3} \mathrm{~J}_{\mathrm{H}-\mathrm{H}}=9.6 \mathrm{~Hz},{ }^{2} \mathrm{~J}_{\mathrm{H}-\mathrm{H}}=14.7 \mathrm{~Hz}, \mathrm{CH}_{2}-\mathrm{Ar}\right)$. NMR ${ }^{13} \mathrm{C} \delta(\mathrm{ppm}) 300 \mathrm{MHz}, \mathrm{DMSO}-\mathrm{d}_{6}: 171.95$ $\left(\mathrm{C}=\mathrm{O}_{\text {amide }}\right), \quad 165.93 \quad\left(\mathrm{C}=\mathrm{O}_{\text {amide }} \quad\right.$ quinoline $)$, 161.30 $\left(\mathrm{C}=\mathrm{O}_{\text {ester }}\right), \quad 144.83-138.65 \quad\left(\mathrm{C}_{4 \mathrm{a}}-\mathrm{C}_{8 \mathrm{a}}\right), 136.61$ $\left(\mathrm{Cq}_{\mathrm{ar}}\right), 133.98\left(\mathrm{Ct}_{\mathrm{ar}}\right), 128.34\left(\mathrm{Ct}_{5}\right), 127.49\left(\mathrm{Ct}_{7}\right)$, $124.24\left(\mathrm{Ct}_{\mathrm{ar}}\right), 122.82\left(\mathrm{Ct}_{\mathrm{ar}}\right), 121.51$ ( $\left.\mathrm{Ct}_{\text {ethylenic }}\right), 118.92$ $\left(\mathrm{Ct}_{\mathrm{ar}}\right), 118.49\left(\mathrm{Ct}_{\mathrm{ar}}\right), 118.26\left(\mathrm{Cq}_{\mathrm{ar}}\right), 114.29\left(\mathrm{Cq}_{\text {ethylenic }}\right)$, $112.03\left(\mathrm{Ct}_{\text {indol }}\right), 110.03\left(\mathrm{Cq}_{\text {indol }}\right), 57.31(* \mathrm{CH}-\mathrm{N})$, $52.51\left(\mathrm{CH}_{3}-\mathrm{O}\right), 26\left(\mathrm{CH}_{2}-\mathrm{Ar}\right)$.

Mass Spectrometry: $[\mathrm{MH}]^{+} \mathrm{m} / \mathrm{z}=468$, $\mathrm{m} / \mathrm{z}=470(\mathrm{M}+2)$.

\section{References}

1- E.A. Ashley, M. Dhorda, R.M. Fairhurst, Ali R. Keramati, M.D. Mohsen Fathzadeh, A. Mani, Spread of Artemisinin Resistance in Plasmodium falciparum malaria, N. Engl. J. Med., 2014, 371, 411-423.

2- $\quad$ G. Y. Lesher, E. J. Froelich, M. D. Gruett, J. H. Bailey and R. P. Brundage, "1,8-Naphthyridine Derivatives: A New Class of Chemotherapeutic Agents", J. Med. Pharm. Chem., 1962, 5, 1063 1065.

3- A. S. Wagman, M. P. Wentland, Quinolone antibacterial agents, J. Compreh. Med. Chem. II., 2007, 7, 567-596.

4- S. Emami, A. Shafiee and A. Foroumadi, Quinolones: Recent Structural and Clinical Developments, Iran. J. Pharm. Res., 2005, 3, 123-136.

5- RF. Grossman, P-R. Hsueh, SH. Gillespie, F. Blasi, Community-acquired pneumonia and tuberculosis: differential diagnosis and the use of fluoroquinolones, Int. J. Infect. Dis., 2014, $18,14-21$.

6- $\quad$ N. C. Desai, B. Y. Patel \& B. P. Dave. Synthesis and antimicrobial activity of novel quinoline derivatives bearing pyrazoline and pyridine analogues, J. Med. Chem. Res., 2016, 26, 109-119.

7- G. R. Newcome et W.W. Paudler, Contemporary Heterocyclic Chemistry, John Wiley and Sons; New York, 1982.

8- F. Sliman, M. Blairvacq, Durieu, E. Meijer, L. Rodrigo, J. Desmaële, D. Bioorg, Identification and structure-activity relationship of 8-hydroxy-quinoline-7-carboxylic acid derivatives as inhibitors of Pim-1 kinase, Med. Chem. Lett., 2010, 20, 2801.
9- G. Roma, G. Grossi, M. Di Braccio, D. Piras, V. Ballabeni, M. Tognolini, S. Bertoni, E. Barocelli, 1,8-Naphthyridines VII. New substituted 5-amino[1,2,4]triazolo[4,3a] $[1,8]$ naphthyridine-6-carboxamides and their isosteric analogues, exhibiting notable antiinflammatory and/or analgesic activities, but no acute gastrolesivity, Eur. J. Med. Chem., 2008, 43, 1665.

10- G. Venkat Reddy, S. Ravi Kanth, D. Maitraie, B. Narsaiah, P. Shanthan Rao, K. Hara Kishore, U.S.N. Murthy, B. Ravi, B. Ashok Kumar, T. Parthasarathy, Design, synthesis, structureactivity relationship and antibacterial activity series of novel imidazo fused quinolone carboxamides, Eur. J. Med. Chem., 2009, 44, 1570 .

11- I. Tomassoli, L. Ismaili, M. Pudlo, C. de los Ríos, E. Soriano, I. Colmena, L. Gandía, L. Rivas, A. Samadi, J. Marco-Contelles, B. Refouvelet, synthesis, biological assessment and molecular modeling of new dihydroquinoline-3-carboxamides and dihydroquinoline-3-carbohydrazide derivatives as cholinesterase inhibitors, and $\mathrm{Ca}$ channel antagonists, Eur. J. Med. Chem., 2011, 46, $1-10$.

12- K. Tsuji, G. Spears, K. Nakamura, T. Tojo, N. Seki, A. Sugiyama, M. Matsuo. Quinoline3-carbothioamides and related compounds as novel immunomodulating agents. Bioorg. Med. Chem. Lett., 2002, 12, 2427-30.

13- P. Hochegger, J. Faist, W. Seebacher, R. Saf, P. Mäser, M. Kaiser, R. Weis. Synthesis and structure-activity relationships for new 6fluoroquinoline derivatives with antiplasmodial activity, Med. Chem. Lett., 2019, 27, 2052-2065.

14- A. Trivedi, D. Dodiya, J. Surani, S. Jarsania, H. Mathukiya, N. Ravat, V. Shah, Facile onepot synthesis and antimycobacterial evaluation of pyrazolo[3,4d] pyrimidines, Arch. Pharm., 2008, 341, 435-439.

15- N. Muruganantham, R. Sivakumar, N. Anbalagan, V. Gunasekaran, J.T. Leonard, Synthesis, anticonvulsant and antihypertensive activities of 8-substituted quinoline derivatives, Biol. Pharm. Bull., 2004, 27, 1683-1687.

16- B. Chakraborty, D. Dutta, S. Mukherjee, S. Das, N.C. Maiti, Synthesis and biological evaluation of a novel betulinic acid derivative as an inducer of apoptosis in human colon carcinoma cells (HT-29), Eur. J. Med. Chem., 2015, 102, 93-105.

17- X. Bu, J. Chen, LW. Deady, C. L. Smith, B. C. Baguley, D. Greenhalgh, S. Yang, WA. Denny. Bioorg, Synthesis and cytotoxic activity of $\mathrm{N}$-[(alkylamino)alkyl]carboxamide derivatives of 7-oxo-7H-benz[de]anthracene, 7-oxo-7Hnaphtho[1,2,3-de]quinoline, and 7-oxo-7Hbenzo[e]perimidine, Med. Chem. Lett., 2005, 13,3657 . 
18- C. A. Townsend, A. M. Brown, Nocardicin A: biosynthetic experiments with amino acid precursors, J. Am. Chem. Soc., 1983, 105, 913-918.

19- M. G. Moloney, Excitatory amino acids, Nat. Prod. Rep., 1999, 16, 485-498

20- A. B. Hughes, Amino Acids, Peptides and Proteins in Organic Chemistry: Building Blocks, Catalysis and Coupling Chemistry; ed by. A. B. Hughes: Wiley-VCH, Weinheim, 2011, pp. 83-114.

21- Y. Ohashi, R. Onuma, T. Nagakuma, T. Ogawa, R. Naude, K. Nokihara, K. Muramoto, Antioxidant properties tripeptides revealed by a comparison of six different assays, Food Sci. Technol. Res., 2016, 21, 695-704.

22- QY. Wei, H. Jiang, JX. Zhang, C. Zhang, PF. Guo, Antimicrobial activities of the cinnamoyl amide of amino acid derivatives, Asian J. Chem., 2012, 24, 2383-2388.

23- H. G. Ghalehshahi, S. Balalaie, A. Aliahmadi, R. Moghimi, Synthesis of 4-N- $\alpha$-coumaryl amino acids and investigation of their antioxidant, antimicrobial activities and fluorescence spectra. Amino Acids., 2018, 50, 1461-1470.

24- Y.Shivaraj, Malenahalli, Naveen, R. Giriyapura, Vijayakumar, Doyijode, B. Aruna Kumar, Design, Synthesis and Antibacterial Activity Studies of Novel Quinoline Carboxamide Derivatives, J. K. Chem. Soc., 2013, 57, 241-245.

25- A. Pinazo, M.A. Manresa, A.M. Marques, M. Bustelo, M.J. Espuny, L. Pérez, Amino acidbased surfactants: New antimicrobial agents, Adv. Colloid Interfac Sc., 2016, 228, 17-39.

26- R. Ammar, M. Zayed, Sulaiman. PH-titration, synthesis and antimicrobial activity of Co(II) complexes of Girard $\mathrm{T}$ and amino acids, Life Sci J., 2014, 11, 437-443.

27- I. Irwansyah, Li YQ, Shi W, Qi D, Leow WR, Tang MBY, Li S, Chen X, Gram-positive antimicrobial activity of amino acid-based hydrogels, Adv. Mater., 2015, 27, 648-654.

28- Junyong Zhang, Xiaokang Ke, Chao Tu, Jun Lin, Jian Ding, Liping Lin, HoongKun Fun, Xiaozeng You, Zijian Guo, Novel Cu(II)quinoline carboxamide complexes: Structural characterization, cytotoxicity and reactivity towards 5'-GMP, BioMetals., 2003, 16, 485-496.

29- Y. Filali Baba, Yusuf Sert, Youssef Kandri Rodi, Sonia Hayani, Joel T. Mague, Damien Prim, Jerome Marrot, Fouad Ouazzani Chahdi, Nada Kheira Sebbar, El Mokhtar Essassi, Synthesis, crystal structure, spectroscopic characterization, Hirshfeld surface analysis, molecular docking studies and DFT calculations, and antioxidant activity of 2-oxo1,2-dihydroquinoline-4-carboxylate derivatives, J. Mol. Struct., 2019, 1188, 255-268.

30- Y. Filali Baba, Y. Kandri Rodi, K. Misbahi, F. Chahdi Ouazzani, A. Kerbal, E.M. Essassi, Synthesis and reactivity of new heterocyclic systems derived from quinoline, J. Mar. Chim. Heterocycl., 2014, 13: 72-80.

31- M. Brenner, W. Huber, Preparation of a-amino acid esters by alcoholysis of the methyl esters, Helv. Chim. Acta, 1953, 36, 1109-1115.

32- S.Y. Han, Y.A. Kim, Recent development of peptide coupling reagents in organic synthesis, Tetrahedron, 2004, 60, 2447-2467.

33- MRS Zaidan, A. Noor Rain, AR. Badrul, A. Adlin, A. Norazah, I. Zakiah, In vitro screening of five local medicinal plants for antibacterial activity using disc diffusion method, Trop. Biomed., 2005, 22, 165-170.

34- S. Bouhdid, J. Abrini, A. Zhiri, M.J. Espuny, A. Manresa, Investigation of functional and morphological changes in Pseudomonas aeruginosa and Staphylococcus aureus cells induced by Origanum compactum essential oil, J. Appl. Microbiol., 2009, 106, 1558-1568. 